\title{
TRABALHO DOCENTE E VALORES: EM QUESTÃO AS NOVAS TECNOLOGIAS DE INFORMAÇÃO E COMUNICAÇÃO'
}

\author{
ATTITUDES TOWARDS COMPUTER: ELABORATION AND \\ VALIDATIONOFASCALE
}

Sônia Maria Guedes GONDIM²

\begin{abstract}
RESUMO
Este éo segundo artigo de uma série que pretende apresentar algumas considerações acerca das relações entre as tecnologias de informação e comunicação, as organizações educacionais, os valores e o trabalho docente. O objetivo principal deste artigo é o de discutir algumas conseqüências das tecnologias de informação e comunicação, especialmente do computador, no trabalho docente. Para uma compreensão mais abrangente do assunto dividimos o texto em três pequenas partes: i) a importância do trabalho na vida humana; ii) os valores relacionados ao trabalho docente e iii) o uso dos computadores na educação.
\end{abstract}

Palavras-chaves: trabalho, trabalho docente, valores de docentes, computadores na educação.

\begin{abstract}
This article is Ihe second of a series presenting some considerations on the relations between information and communication technologies, education organizations and values and lhe academic work of the teacher. The main purpose ofthis article is to discuss some consequences of information and communication tecnologies, particulary those related to Ihe use of the computer in academic work. In arder to have a more comprehensive understanding of the subject, the text is divided into three parts: i) the importance of work in human life; ii) the values related to academic work and iii) the use of computers in education.
\end{abstract}

Key-words: job, teaching, teacher's job, téachers'values, computers in education.

\footnotetext{
(1) Este artigo foi redigido a partir da tese de doutorado apresentada pela autora ao Programa de Pós-graduação do Instituto de Psicologia da Universidade Federal do Rio de Janeiro, sob a orientação do Professor Helmuth Kruger, cujo título é "Motivos e valores relacionados ao trabalho docente na Sociedade da Informação" (1998).

(2) Professora Adjunta do Departamento de Psicologia da Universidade Federal da Bahia.
} 


\section{INTRODUÇÃO}

Embora não seja uma novidade na história da humanidade, uma das conseqüências das novas tecnologias foi a de colocar em dúvida a importância do trabalho para o ser humano, uma vez que elas o substituem em tarefas consideradas repetitivas, enfadonhas e até mesmo perigosas, que a nosso ver não são pertinentes à atividade do professor. Sob esse aspecto conseguimos visualizar com facilidade quais são as vantagens das novas tecnologias. Isso seria muito bem vindo se não houvesse o agravante de que na nossa sociedade a maior parte da população depende do trabalho remunerado, muitas vezes apresentado sob a forma de emprego, onde não se garante qualquer relação mais significativa para o homem, exceto a da recompensa material.

Se na nossa sociedade o trabalho está fortemente associado a uma mera relação de emprego que garante a sobrevivência e se as mudanças tecnológicas aliadas a políticas econômicas muitas vezes equivocadas estão contribuindo para o extinção de empregos, indubitavelmente estaremos diante de pelo menos dois desafios: o de garantir a sobrevivência da população sem emprego e o de defender a importância social do trabalho. Ainda que de considerável importância, não iremos tratar do primeiro desafio, pois nos obrigaria a fazer uma digressão deveras extensa, ao contrário do segundo desafio que nos reporta ao eixo central de nossa discussão, qual seja, a do significado do trabalho na vida pessoal.

A rigor encontramos exemplos na história que denunciam os antagonismos e paradoxos das relações sociais de trabalho. Se observarmos com cuidado, as concepções sobre trabalho não parecem tratá-lo da mesma maneira em termos de seu significado para o homem. Longe disso, o trabalho parece despertar sentimentos ambivalentes.
Para a Mitologia grega, por exemplo, a origem do trabalho é atribuída à perda do privilégio de partilhar o mundo dos deuses e um castigo divino (Graves, 1992, p.9-10; 23-24).

A história sugere que o poeta Hesíodo (ed. 1991), que viveu em meados do século VIII antes de nossa era, representava uma voz isolada na Grécia Antiga, ao afirmar que o trabalho é uma atividade capaz de assegurar a justiça entre os homens, os diferenciando de outros animais.

Arendt (1983), analisando a sociedade grega dessa época distinguiu três atividades fundamentais da vida humana: o labor (atividade de consumo), o trabalho (atividade cultural) e a ação (atividade política). Acrescenta ainda que os antigos depreciavam o trabalho e o labor, pois achavam que eles faziam com que - homem se submetesse à matéria, assinalando a antítese entre trabalhar e pensar, entre trabalhar e conhecer, dois planos distintos da atividade humana.

Um outro exemplo retirado da história é o de Calvino ( 1509-1566 ) que introduziu a noção de predestinação, pregando que quando de sua vinda ao mundo, cada um já trazia a sua condição de eleito ou excluído e de que, portanto, diante de um Deus tão arbitrário, os homens se encontravam sozinhos. Nesse caso, o trabalho que rendesse bons frutos seria a única forma de expressão visível da predestinação, ou seja, um sinal da graça concedida. Em poucas palavras, o trabalho era um privilégio dos agraciados (Battaglia, 1958).

A partir do exposto anteriormente, torna-se claro que o trabalho é avaliado mais em seus aspectos negativos do que positivos e deve ser entendido como um conjunto de atividades diversificadas para as quais se atribui importância social diferenciada.

Por que ressaltar isso? Primeiro, porque em qualquer forma de organização social os homens experimentam sentimentos às vezes 
antagônicos em relação ao trabalho e, segundo, porque ao longo do desenvolvimento da humanidade, principalmente a partir do processo de industrialização, a atividade que ganhou maior repercussão foi a do labor, a de mais baixo status (Arendt, 1983). Como havíamos afirmado, acreditamos que isso seja decorrente do crescente surgimento da atividade apresentada sob a forma de emprego, destituída de significado mais concreto para o homem. Isso nos leva a crer que é o emprego que tende a desaparecer com o avanço tecnológico e não o trabalho como atividade humana.

Em nossa opinião, uma definição do trabalho que defende sua importância para o homem é a de Friedman (1973, p.20), um sociólogo de orientação marxista, que o caracteriza como um conjunto de ações que se utilizam do cérebro, das mãos, de instrumentos ou de máquinas que capacitam o homem a modificar a matéria e, ao mesmo tempo, auto-transformar-se. É o trabalho que dirige o homem a um plano superior, embora paradoxalmente reconheçamos o abuso e a exploração a que muitos se viram e se vêem sujeitos no decorrer da história.

Em poucas palavras, o trabalho humano é fruto da ação intencional - o que a distingue da escravidão - de transformação da matéria, realizada com duas finalidades básicas: i) garantia da sobrevivência e a ii)inserção no contexto sócio-cultural, favorecendo o desenvolvimento da identidade social e profissional. Em resumo, pelo trabalho o homem aumenta o seu controle sobre a natureza e progride no seu auto-domínio.

A pergunta que fazemos é muito simples: será que as atividades oferecidas na sociedade atual sob a forma de emprego permitem alguma modificação e a auto-transformação humana ? Será que a relação do homem como trabalho na sociedade industrial não assumiu um caráter meramente instrumental, ou seja, de emprego, de modo a não promover o crescimento e o aperfeiçoamento da pessoa?

Pensamos que é essa relação instrumental que favorece o esvaziamento da atividade humana no trabalho, pois visa garantir apenas a sobrevivência econômica (em alguns casos nem isso), sem desenvolver um compromisso mais forte com a transformação humana.

Olhando sob esse ângulo é compreensível que o trabalho seja visto como um fardo a ponto de se desejar sua eliminação, muitas vezes prometida pelas novas tecnologias.

As transformações pelas quais passa $o$ mundo do trabalho estão servindo de ponto de partida para a reflexão de inúmeros autores (Antunes,1995; Bell, 1977;Coriat, 1994, 1989; Friedmann, 1983; Galbraith, 1996; Howard, 1995; Kurz, 1993; Mattoso, 1995, 1994; Negroponte,1995;Offe, 1989; Rebecchi, 1990; Rifkin, 1995; Schaff, 1995) que alertam para o fato de que suas conseqüências nos planos tecnológicos, ecológicos, sociais, políticos, econômicos e morais são pouco controladas.

Poderíamos interromper neste ponto nossas considerações e indagar: quais as conseqüências disso para o entendimento do trabalho docente?

As mudanças tecnológicas também estão afetando as organizações educacionais e o trabalho docente. Apesar de haver uma crença compartilhada de que a sociedade da informação demanda um maior nível instrucional da população, o que, a princípio, reafirmaria a importância do trabalho do professor e das instituições educacionais, não podemos nos esquivar de dar respostas mais consistentes para duas indagações: será que as novas tecnologias poderão vir a substituir o professor ou serão suas aliadas na redefinição de metodologias instrucionais? Essas mesmas tecnologias irão compelir o professor a rever o seu papel na sociedade e questionar os valores que dão sustentação ao 
seu trabalho ou, a rigor, ratificarão os já existentes?

Nosso esforço será dirigido no sentido de tentar responder a essas questões.

\section{VALORES RELACIONADOS AO TRABALHODOCENTE}

O trabalho de mestres e professores envolve o educar. Educar está ligado ao afeto, que vai muito além da mera atividade de instrução, que é a transmissão de informações e o treinamento específico de habilidades. $\mathrm{O}$ educar é um ato moral da conduta do professor, ou seja, exige responsabilidade e autodisciplina, enquanto deveres; motivação e amor, enquanto expressões de afeto (Spranger, 1960). Afinal, mestres e professores se dedicam à formação integral da pessoa, preparando-a para a vida em sociedade. E o processo básico para se conseguir isso é a discussão e o diálogo que se estabelece entre professor e aluno. A noção de discussão deve ser distinguida tanto da noção de conversão quanto da de debate. Enquanto a conversão envolve simplesmente a troca de pontos de vista, a discussão visa ampliá-los. Enquanto no debate cada um defende apenas as suas opiniões ao invés de colocá-las em dúvida, na discussão a crítica é fundamental (Rembert, 1995).

O mestre e o professor ocupam um lugar fundamental na aquisição do conhecimento humano, uma vez que na nossa interpretação o conhecimento não é um processo natural, ao contrário, é conseqüência da intervenção pedagógica e da maturação biológica e cognitiva. Em síntese, sabemos que o homem surge no mundo em virtude das leis naturais, mas somente a socialização a que ele se submete é que garante o seu desenvolvimento como ser social. É através do encontro e do diálogo que o conhecimento se torna acessível. É em virtude do processo educativo e do trabalho de mestres e professores que os valores que sustentam a sociedade,em grande parte, vão se consolidando. Por essa razão devemos procurar saber quais são os valores que orientam o trabalho docente. Reconhecer esses valores se torna importante por acreditarmos que os docentes ocupam lugar central no processo de influenciação social, contribuindo sobremaneira para a formação dos futuros cidadãos, que poderão vir a ser bem sucedidos ou não numa sociedade altamente instável, sujeita a bruscas mudanças na economia, nos processos sociais, na cultura e na política.

Talvez fosse oportuno fazer breves comentários acerca dos valores para posteriormente tentar discutir sobre aqueles que dão sustentação ao trabalho docente.

Os valores podem ser definidos como disposições psicológicas positivas dirigidas a entes que se situam tanto no plano concreto quanto abstrato. De caráter mais genérico que as atitudes, os valores ocupam uma posição mais central no sistema cognitivo da pessoa e têm como um dos seus objetivos principais orientar condutas no trabalho, no lazer, na ciência, na política, na moral, no Direito, dentre tantas outras facetas da vida humana em sociedade (Krüger, 1995). Em síntese, a importância dos valores decorre de seu caráter pragmático.

Enquanto a Filosofia se atém à reflexão no plano teórico acerca do que são valores e de seu papel na vida humana, os psicólogos procuram dirigir sua investigação empiricamente, levando em conta como os valores são formulados, aprendidos e vivenciados pela pessoa, ou seja, a experiência do sujeito que valora (Rockeach, 1981).

Em resumo diríamos que o entendimento dos valores deve contemplar tanto o plano subjetivo (da pessoa que valora) quanto o plano objetivo (do objeto depositário de valor).

Para interpretarmos os valores envolvidos no trabalho docente nos inspiramos na tipologia apresentada por Spranger em seu livro Formas de Vida (1948), autor que segue a tradição da 
Escola de Baden que distingue as ciências em duas: as relativas à natureza e as afetas às atividades do espírito. Spranger (1948) ao buscar conciliar os planos filosófico e psicológico defende a posição de que os valores compõem a unidade do eu e desenham a interação do sujeito com o coletivo e o transubjetivo, fornecendo sentido e integridade à vida pessoal.

Os valores foram divididos em número de seis: econômico, teórico, estético, ético-religioso ${ }^{3}$, social e político. Segundo Spranger (1948), a unidade da personalidade é influenciada pela disposição hierárquica dos valores, delineando um tipo psicológico específico. Desse modo teríamos o tipo de personalidade econômico, o tipo de personalidade estético e assim sucessivamente, tendo em vista o tipo de valor predominante e suas relações com os demais valores.

O valor econômico revela um interesse pessoal utilitarista, cuja preocupação maior é com a conservação da vida e com seus aspectos materiais. O valor teórico diz respeito à importância da busca contínua do conhecimento e da verdade, almejando proposições ou enunciados fundamentados, que facultem a construção de argumentos reconhecidamente válidos. $O$ valor estético revela uma atitude desinteressada diante do mundo, ou seja, mais contemplativa, em que a pessoa procura uma conciliação entre a expressão e a impressão, entre a representação e a vivência, visando alcançar uma harmonia entre a forma e a matéria, o racional e o sensível, a individualidade e a validade universal. O valor social denuncia o interesse na ajuda ao próximo e na cooperação mútua, ao fomentar a comunhão de valores nas relações interpessoais. O valor político revela o interesse pelo poder, pelas relações de domínio, controle e subordinação. Por último, o valor ético-religioso ${ }^{4}$ faz com que a pessoa invista na atitude religiosa e moral.

Ainda que a princípio reconheçamos que todos os seis valores tenham importância para o docente, procuraremos destacar aqueles que, em nossa opinião, ocupam posições privilegiadas na sua hierarquia de valores pessoais.

Poucos duvidariam da afirmação de que um dos valores centrais de sustentação do trabalho do professor seja o teórico. O que o orienta é a busca do conhecimento válido, ainda que alguns o considerem inacessível. Além disso o professor tem a responsabilidade na difusão desse conhecimento, através, por exemplo, de seus ensinamentos. Em virtude do grande poder de influência do professor sobre o estudante, constitui falta grave a transmissão de conhecimentos e informação equivocados. Em suma, o professor deve agir com muita competência e segurança na seleção dos conteúdos a serem apresentados em sala de aula.

Talvez o segundo valor seja o estético. $O$ professor vê na sua profissão sua razão de ser e a ama acima de tudo, tendo prazer de exercê-la. O estético é visualizado na

\footnotetext{
(3) Cronologicamente o termo ética antecede o termo moral em pelo menos três séculos, o primeiro, de origem grega, passou a ser empregado por volta do século IV antes de nossa era e o segundo de origem latina foi proposto por Cícero no ano I antes de nossa era. Se antes tinham a mesma significação, sendo empregados indistintamente, na Filosofia Moderna assumiram sentidos diversos. A Ética passou a ser considerada como um campo de análise filosófica que se dedica aos fundamentos racionais do dever e da responsabilidade envolvidos nas condutas interpessoais, enquanto que a moral se restringiu às práticas e condutas que regem a vida dos grupos humanos e da sociedade em geral, nas quais a intencionalidade é fundamental na compreensão das regras que prescrevem as relações interpessoais ( Krüger, 1997 ). Mantemos o termo utilizado na tradução do trabalho de Spranger, mas exploramos, a rigor, os aspectos ligados à conduta moral dos professores.

(4) Aqui podemos considerar a Ética de duas formas: uma decorrente da dedução da Teologia Religiosa como, por exemplo, o atolicismo, o islamismo, o judaismo, o budismo, o protestantismo etc; e outra fruto da faculdade da razão, valendo-nos de recursos racionais ao invés de dogmas religiosos. Spranger parece tê-la usado mais no primeiro sentido.
} 
apresentação de uma argumentação consistente e na oratória que seduz o estudante e o instiga a buscar o conhecimento e o auto-aperfeiçoamento.

Além dos valores teóricos e estéticos, uma das preocupações centrais do professor é como auto-conhecimento e auto-domínio do estudante, mais do que com a transmissão do conhecimento geral ou de uma técnica em especial. Em decorrência disso podemos inferir que o valor social, ou melhor, a ajuda ao próximo no seu crescimento intelectual, moral, físico e político deve ocupar um lugar de destaque na hierarquia pessoal de valores dos docentes. Van Gogh, numa carta endereçada a seu irmão, menciona uma frase dita pelo pintor americano Whistler em relação a uma aquarela: "- É verdade que a pintei em duas horas, mas trabalhei anos e anos para poder fazer em duas horas..." (Gusdorf, 1967, p. 119). Em suma, o mestre e o professor trabalham pela construção do conhecimento, pela sua difusão e pela realização alheia.

Os aspectos econômicos e políticos não constituem valores para os docentes. O aspecto econômico é fácil constatar, ao considerarmos os salários desses profissionais. Isto não quer dizer que os professores não necessitem de recompensas financeiras mais justas, muito pelo contrário, mas o que queremos chamar atenção é para o fato de que a satisfação e o prazer do professor estão no seu trabalho propriamente dito e na sua relação com os alunos. Uma pessoa que desejasse enriquecer rapidamente, muito provavelmente descartaria de imediato a docência como atividade principal.

O mais difícil de entender é o aspecto político, haja vista a forte crença de que os professores são formadores de consciências críticas. O valor político, entretanto, está sendo tratado aqui como equivalente ao interesse de exercer o poder e domínio sobre o estudante, em que está em jogo a subordinação. Pensamos que esse interesse entraria em conflito com seu papel social de facilitador no processo de desenvolvimento da autonomia do estudante. Isso ficou bastante evidente durante a investigação empírica que realizamos para a tese de doutorado, em que os professores se esquivaram de responder a aspectos políticos envolvidos em seu trabalho, os relacionando ao autoritarismo, ao controle da liberdade de pensamento do estudante e à imposição de uma ideologia (Gondim, 1998).

Identificar valores sociais, teóricos, estéticos e morais na atividade docente não é o bastante, contudo, para compreendermos a extensão de sua atuação profissional, uma vez que ela se dá, em grande parte, na interação com os alunos. Cabe então indagar sobre as expectativas e representações que são construídas em torno do bom professor.

Rangel (1994) estudou as representações sociais ${ }^{5}$ que alunos, pais, professores e funcionários de duas escolas da cidade de Niterói, uma particular e uma pública, sustentavam em relação ao rótulo do bom professor. As qualidades mencionadas se situam, principalmente: i) na postura não autoritária do professor, valorizando o conhecimento já adquirido pelo aluno; ii) na técnica didática adotada em detrimento do domínio do conhecimento; iii) no grau de amizade firmado com os alunos e iv) na clareza e segurança das orientações que faz. Rangel ressalta também que o papel político do professor foi pouco evidenciado.

Seguindo a mesma orientação, Cunha (1996) fez uma pesquisa em 1990 com estudantes universitários, para saber o que eles pensavam ser o bom professor, e para sua surpresa, aqueles que trabalhavam na perspectiva da reprodução do conhecimento, considerada a abordagem dominante, foram os mais bem avaliados. Em pesquisa mais recente, tentando caracterizar as práticas pedagógicas dos professores universitários essa autora encontrou sete, dentre 13 entrevistados, que afirmaram iniciar 0 
processo de ensino a partir da história e da experiência do aluno, permitindo-nos inferir a respeito da influência da perspectiva construtivista do conhecimento entre estes profissionais ${ }^{5}$.

As representações que os alunos, professores, pais e funcionários de escolas e universidades formularam a respeito do bom desempenho docente e do processo de aprendizagem, demonstram os valores envolvidos no trabalho deste profissional.

O que nos chama atenção quando levamos em conta as novas tecnologias no sistema produtivo é que com elas houve uma revalorização da escola básica, na medida em que o trabalhador necessita hoje de habilidades gerais de comunicação, abstração e integração, que são normalmente desenvolvidas durante o período escolar (Freitas, 1993). Cabe esclarecer, contudo, que as tecnologias de informação e comunicação introduzidas nas escolas e universidades destacam apenas o lado técnico da atividade do professor e do processo ensino-aprendizagem, deixando de lado outros aspectos essenciais à qualidade da formação pessoal, que se manifesta em grande parte no contato face-a-face.

Segundo Pinto ( apud Santos, 1994, p. 318), a formação do educador passou a ter destaque durante o I seminário de Educação Brasileira realizado na Universidade Estadual de Campinas em 1978. Dois pontos foram salientados a partir daí: o caráter político da prática pedagógica e o compromisso do educador com as classes populares. $\mathrm{O}$ ato de educar deveria ter primazia sobre $o$ ato de ensinar. As seguintes proposições serviram de base para esta nova orientação: i) há defasagem entre a preparação e treinamento oferecido pelas escolas de formação profissional e a realidade da atividade prática futura, que deve ser minimizada a partir de um suporte teórico e técnico-científico adequado; ii) deve-se cultivar a reflexão como elemento essencial para o desempenho de qualquer atividade prática e iii) a participação crítica do sujeito em todas as esferas da vida pública, ou seja, o exercicio da cidadania deve assumir importância singular na organização da ação coletiva para criação de uma sociedade igualitária. Diante disso, tornou-se fundamental repensar o processo de formação do professor.

Em suma, acreditamos que o trabalho seja um valor para o docente e o seu significado e importância interferem na qualidade de seu desempenho profissional. O que as novas tecnologias têm feito é enfatizar o aspecto técnico da atividade docente, uma vez que elas permitem redefinir não o papel, mas as metodologias de ensino. Sendo assim, não acreditamos que as tecnologias de informação e comunicação venham a substituir o professor, mas com certeza lhe exigirão uma reflexão crítica acerca de como conciliar sua responsabilidade no desenvolvimento das pessoas com a construção da sociedade, uma vez que as escolas e universidades estão sendo chamadas a contribuir cada vez mais para a formação profissional.

\section{COMPUTADORES NA EDUCAÇÃO: REPERCUSSÕES NAS ORGANIZAÇÕES EDUCACIONAIS E NO TRABALHO DOCENTE}

Basta que consultemos algumas edições de apenas um dos periódicos que se dedicam ao emprego de tecnologias na educação como, por exemplo, o Computers and Education para constatarmos a variedade de usos que o computador pode ter para a atividade docente. A despeito de artigos e pesquisas que discorrem

\footnotetext{
(5) A expressão 'representações sociais' é atribuída a Moscovici, que a circunscreve no campo da sociologia do conhecimento de tradição européia, numa oposição a uma psicologia social individua lista norte americana. Representações sociais constituem uma forma de conhecimento produzida socialmente que esboçam uma visão de mundo apoiada no senso comum.
} 
sobre o assunto, os professores, no entanto, sentem-se despreparados para incorporar essa nova ferramenta no exercício cotidiano de sua profissão. Handler (1993), por exemplo, afirma que embora $89 \%$ de programas de educação para professores nos EUA ofereçam oportunidades para treinamento no computador e grande parte destes profissionais reconheça que o uso da tecnologia é cada vez maior na educação, somente $29 \%$ deles sente confiança suficiente para utilizar a máquina para fins de ensino. A rigor, os cursos de computadores disponíveis ao professor se dirigem mais para o aprendizado de habilidades técnicas de manuseio da máquina, do que para os métodos através dos quais se possa integrar os computadores no currículo escolar e utilizá-los como recurso didático no espaço da sala de aula. Numa amostra de 133 professores da pré-escola e do ensino elementar, apenas 18, $8 \%$ sente segurança para usar o computador no ensino. Os fatores que contribuem para a segurança na utilização do computador são os seguintes: i) a quantidade de vezes em que o computador foi usado no curso; ii) o número de vezes em que o estudante (futuro professor) pôde observar o uso do computador no ensino e em outras situações e iii) o grau de familiaridade com o computador antes do curso.

No que tange ao tipo de utilização que é feita, Handler (1993) menciona que, inicialmente, grande parte dos professores faz uso de editores de textos e, posteriormente, avalia a pertinência de alguns programas educativos para auxiliar o processo de ensinoaprendizagem. A possibilidade de uso do computador como recurso instrucional na sala de aula, porém, é muito pouco mencionada. Em síntese, o problema está alocado na dificuldade encontrada por professores, escolas e universidades de integrar o computador no ensino. O desafio é conciliar o material adequado, o momento e o local apropriados.
Ainda que muitos professores não se sintam suficientemente preparados para usar o computador como recurso instrucional, um número representativo de projetos dessa natureza é desenvolvido em várias partes do mundo e em todos os graus de ensino. $O$ computador, por exemplo, é usado para treinar a observação sistemática e a análise do comportamento animal em uma situação criada virtualmente, fazendo com que o aluno formule assertivas de observação mais descritivas e menos avaliativas, permitindo através de feedbackimediato, orientar construtivamente - seu processo de aprendizagem, diferentemente da observação só do vídeo, simplesmente passiva e não interativa. $O$ hipertexto, um sistema de aprendizagem nãolinear que torna possível diversos vínculos a partir do texto original permitindo ao aluno orientar os seus estudos e se aprofundar de acordo com as suas necessidades, também é bastante utilizado.

Esses exemplos ilustram o salto muito grande em termos de evolução histórica da linguagem escrita. Se durante séculos a humanidade só dispunha da linguagem oral ou escrita à mão e muito depois passou a contar com a imprensa de caracteres móveis, a partir da invenção da eletricidade e do computador, tudo mudou. As possibilidades de comunicação se ampliaram substancialmente. Mcluhan escrevia sobre Aldeia Global em 1964 e a teia de extensão mundial, ou seja, o WWW (World Wide Web) viabilizou esse projeto. Programas de acesso ao WWW, como o Netscape foram criados, juntamente com sistemas de busca como, por exemplo, o Yahoo e o Altavista, que permitem a cada um procurar as informações de que necessita a partir de palavras, expressões ou assuntos (Barger, 1996). E as conquistas se ampliam a cada ano, com o computador auxiliando o desenvolvimento intelectual dos estudantes.

Dois estudos de casos podem servir de exemplo do uso do computador como auxiliar no processo de tomada de decisão. Blanford, 
Cross \& Scanlon (1994) discorrem acerca de um sistema criado para assessorar estudantes de engenharia no desenho de seus projetos, visando garantir maior qualidade do trabalho. O sistema foi construído de forma a possibilitar o diálogo com o estudante de modo a levá-lo a refletir acerca dos problemas correntes e das estratégias escolhidas para sua resolução oferecendo, inclusive, informações adicionais sempre que solicitado. O princípio básico é o de que o diálogo é essencial no processo de aprendizagem e um sistema computacional poderia ajudar o estudante a pensar melhor as alternativas. $O$ outro exemplo foi retirado do artigo de Wild \& Winniford (1993) sobre uma experiência de cooperação entre duas universidades, visando a solução de problemas complexos. O intercâmbio foi feito através de electronic mail. Os estudantes avaliaram a experiência como enriquecedora para o aprendizado e o aprimoramento do processo de tomada de decisão, pois de certa forma, eles se sentiram compelidos a melhorar suas análises e a criar estratégias para que o trabalho em grupo fosse produtivo, tornando fértil a aprendizagem colaborativa.

Procedendo a uma análise de conteúdo de quase 3000 temas de artigos, conferências e dissertações na área, apresentados entre os anos de 1988 e 1989, Ely (1990) concluiu que uma das mais fortes tendências éa do desenho e desenvolvimento de produtos e procedimentos instrucionais. Numa escala micro de investigação, os estudos e pesquisas se dirigiram tanto para as habilidades, análise de tarefas, características e estratégias motivacionais do aprendiz, quanto para o desenvolvimento de sistemas especialistas, sistemas de resolução de problemas e vídeo interativo. Na escala macro de análise os esforços se dirigiram para a definição de metas e objetivos, o arranjo sistemático de componentes e a educação à distância. $\mathrm{O}$ grande trunfo do computador é o de favorecer o aprendizado independente das instituições educacionais.
Talvez fosse pertinente aprofundar um pouco mais a questão do ensino à distância a partir de uma pergunta que serviu de título para um artigo de Ohler (1991), cuja tradução para o português seria: Por que educação à distância? Uma das questões que nortearam Ohler foi a preocupação com as mudanças que podem ocorrer na concepção de aprendizagem. O ensino à distância, e aqui, no nosso caso, o ensino mediado por formas de tecnologias de informação e comunicação, é uma exigência do mundo atual. Dois aspectos essenciais fazem parte desse processo: a descentralização da instrução, que passa a atingir um maior número de pessoas dispersas geograficamente, e a cooperação e integração entre essas mesmas pessoas através de redes de comunicação. Embora devamos reconhecer que tal modalidade não substitui os métodos tradicionais de ensino, apenas criando novas alternativas, as vantagens são enormes. Uma delas é o rompimento de distâncias, permitindo a participação de pessoas que se encontram impedidas de deslocamento como, por exemplo, presidiários e acamados, ou que, por opção, residam em áreas rurais. O trabalho no mundo de hoje exige um aprendizado continuado e a tecnologia está oferecendo esta oportunidade de atualização contínua.

$\mathrm{Na}$ Internet, a rede mundial de computadores, encontramos relatos de experiências de ensino à distância mediado por tecnologias de informação e comunicação, em andamento desde a segunda metade da década de 80, por iniciativa de centros de ensino de pós-graduação como, por exemplo, o programa de Virtual Classroom do Instituto de Tecnologia de Nova Jersey e o programa de Aprendizagem Colaborativa Inter-institucional Mediada por Tecnologias de Informação, que reuniu a Universidade de Maryland e a Universidade do Arizona, ambos desenvolvidos nos EUA, embora se admita que outros países já estejam se dedicando a esta modalidade de ensino há algum tempo. 
Em síntese, a educação à distância ${ }^{6}$ é uma opção tecnológica que se apresenta mundialmente e pode ser uma forma de democratização do ensino (Mata, 1995).

É preciso considerar a título de conclusão parcial que a experiência do uso do computador na atividade docente não contempla integralmente os meandros da profissão em questão. $O$ destaque maior é dado à instrução, ou seja, ao aspecto técnico, em detrimento da educação integral do aluno ou estudante, que é uma das atribuições mais importantes a que deve se dedicar todo professor.

O computador está invadindo as organizações formais, as escolas e o processo de ensino-aprendizagem, mas o professor não se sente devidamente preparado para incorporá-lo no seu dia-a-dia de trabalho. É exigido, antes de mais nada, pensar em alternativas que viabilizem o aproveitamento das conquistas técnicas no processo pedagógico, que se apóia em concepções acerca de como se aprende e qual o papel do professor na facilitação da aprendizagem. $\mathrm{O}$ relato de algumas experiências revelam que o computador pode auxiliar no processo de tomada de decisão, na simulação de situações e no treino, por exemplo, da observação científica e do raciocínio. Oferece também outras oportunidades de ensino à distância favorecendo a integração, a comunicação e o trabalho colaborativo na solução de problemas complexos.

\section{CONSIDERAÇÕES FINAIS}

No início deste artigo mencionamos que um de nossos objetivos é o de contribuir para o aprofundamento das discussões sobre as repercussões das novas tecnologias nas organizações educacionais e no trabalho docente.

No caso das organizações educacionais é inegável que a tecnologia está rompendo limites geográficos, facilitando o ensino individualizado e o auto-aprendizado dando, conseqüentemente, maior autonomia ao aprendiz e contribuindo para o seu esforço permanente de atualização.

Como Clegg, Waterson E Carey (1994) salientam, o fracasso na informatização em escolas é devido, em parte, ao equívoco de se acreditar que a infra-estrutura material e financeira seja suficiente. Muitas vezes, as reflexões acerca dos métodos de ensino, da didática, do papel do docente e do aluno no processo de ensino-aprendizagem e do sistema de valores que dá suporte as relações do professor com o seu trabalho são deixadas de lado.

Se partirmos do pressuposto de que o trabalho do professor está centrado apenas no processo de ensino-aprendizagem, com certeza seremos obrigados a reconhecer que as tecnologias de informação e comunicação disponíveis podem facilmente substituí-lo na sua tarefa e, neste caso, o receio da perda do emprego encontra justificativa plausível ${ }^{7}$. Se pensarmos, contudo, que o docente tem uma tripla responsabilidade, qual seja, a de colaborar na construção do conhecimento, no seu auto-aperfeiçoamento e na promoção do crescimento e da autonomia do estudante, o problema a enfrentar é outro. É preciso saber de que modo as novas tecnologias poderão vir a auxiliá-lo a cumprir esta tripla missão.

\footnotetext{
(6) As expressões dos docentes em relação ao conhecimento foram as seguintes: "construção cotidiana", "está sempre em movimento", "é produzido a partir dos sujeitos" e "conhecer é trabalhar com a contradição".

(7) No Brasil, desde 1980 a Associação Brasileira de Tecnologia Educacional desenvolve programas de aperfeiçoamento à distância para professores de ensino fundamental. Contando com o apoio da Fundação Roquette Pinto produziu programas de rádio, televisão, ampliando com isso os cursos por correspondência já em funcionamento. A partir de 1993 algumas Secretarias Estaduais e Municipais de Educação do País passaram a colaborar com sucesso para o aperfeiçoamento das práticas docentes (Portes, 1995 ). Apesar da eficácia que o ensino à distância possa vir a ter, algumas dificuldades estão presentes por parte do tele-estudante. Fainholo (1995) cita a falta de compromisso, motivação, concentração e entusiasmo, bem como de disciplina e organização do tempo, necessários para o estudo.
} 


\section{REFERÊNCIAS BIBLIOGRÁFICAS}

ANTUNES, R.(1995) Adeus ao trabalho? Ensaios sobre as metamorfoses e a centralidade. do mundo do trabalho. São Paulo: Cortez/Unicamp.

ARENDT, H. (1983) A condição humana. São Paulo: Forense Universitária.

BATTAGLIA, F. (1958) Filosofia do trabalho. São Paulo: Saraiva.

BELL, D. (1977) O advento da sociedade pós-industrial: uma tentativa de previsão social. São Paulo: Cultrix.

BLANFORD, A.; Cross, N. \& Scanlon, E. (1994) Computers and lhe development of design decision making skills. Computers and Education. v.22 , n. 1/2, p.45 -56.

CLEGG, C.; Waterson, P. \& Carey, N. (1994) Computers supported collaborative working: lesson from elsewhere. Journal of Information Technology. v. 9, p. 85 - 98.

CORIA T, B. (1989) A revolução dos robôs. São Paulo: Busca Vida.

. (1994) Pensar pelo avesso: o modelo japonês de trabalho e organização. Rio de Janeiro: Revan/UFRJ.

CUNHA, M. I. (1996) Ensino com pesquisa: a prática do professor universitário. Cadernos de Pesquisa. Fundação Carlos Chagas. n. 97, p. 31-46.

ELY, D. P. (1990) Trends and issues in educational technology. Educational Media and Technology Yearbook. v. 17, p.5-30.

FAINHOLO, B. (1995) La calidad de la educación a distancia. Tecnologia Educacional. v. 22, n. 123/124, p. 17-21.

FRANCO, M. A. (1997) Ensaio sobre as tecnologias digitais da inteligência. São Paulo: Papirus.

FREITAS, L.C. (1993) Neotecnicismo e formação do educador. In:Alves, N. (org.) Formação de professores: pensar e fazer. São Paulo: Cortez, p. 89-102.
FRIEDMAN, A. (1994) The information technology field: using fields and paradigmas for analyzing technological change. Human Relations. v.47, n.4, p. 367-392.

FRIEDMAN, G. \& Naville, P.(1973) Tratado de sociologia do trabalho. São Paulo: Cultrix.

GALBRAITH, J. K. (1996) A sociedade justa: uma perspectiva humana. São Paulo: Campus.

GONDIM, S.M.G. (1998) A Sociedade da informação, as organizações formais educacionais, valores e o trabalho docente: Possíveis inter-relações. Ética e Filosofia Política. v.3, n.2, pp. 69-102.

GRAVES, R. (1992) Deuses e heróis do olimpo - as maiores aventuras de todos os tempos. Rio de Janeiro: Xenon.

GUSDORF, G. (1967) Professores, para que? Lisboa: Morais editora.

HANDLER, M.G. (1993) Preparing new teachers to use computer technology: perceptions and suggestions for teacher educators. Computers and Education. v. 20,n.2,p.147-156.

HESIODO. (1991) Os trabalhos e os dias. São Paulo: Biblioteca Pólen.

HOWARD, A. (1995) The changing nature of work. San Francisco: Jossey-Bass.

KRÜGER,H.R.(1995) Psicologia das crenças: perspectivas teóricas. Rio de Janeiro. Tese para professor titular - Departamento de Psicologia Social e Institucional da Universidade Estadual do Rio de Janeiro. (1997) Tribuna de Petrópolis. Ética ou moral? 06/04/ p.2.

KURZ, R. (1993) O colapso da modernização. São Paulo: Paz e Terra.

MATA, M.L. (1995) Educação à distância e novas tecnologias - um olhar crítico. Tecnologia Educacional. v. 22, n. 123/124, p. 8 -12, mar/junho. 
MATTOSO, J. (1995) A desordem do trabalho. São Paulo: Scritta.

(org.) (1994) O mundo do trabalho. São Paulo: Scritta.

NEGROPONTE, N.(1995) A vida digital.São Paulo: Companhia das Letras.

OFFE, C. (1989) Trabalho e sociedade. São Paulo: Tempo Brasileiro.

OHLER, J. (1991) Why distance education? ANNALS, AAPSS, n. 514, p.22-33, march.

PORTES, M.M. (1995)Curso à distância por multimeios. Tecnologia Educacional. v.22, n.123/124,p.3-1, mar/jun.

RANGEL, M. (1994) Representações e reflexões sobre o bom professor. Petrópolis: Vozes.

REBECCHI, E. (1990) O sujeito frente a inovação tecnológica. Petrópolis: Vozes.

REMBERT, RB. (1995) Socrates, discussion and moral education. Revue Internationali de l'Education. v. 41, n. 1/2, p. 97-108.
RIFKIN, J. (1995) O fim dos empregos. São Paulo: Makron Books.

ROKEACH, M. (1981) Crenças, atitudes e valores. Rio de Janeiro: Interciência.

SANTOS, L. L. C. P. (1994) Problemas e alternativas no campo da formação de professores. Revista Brasileira de Estudos Pedagógicos/INPEP. v.172, n.I, p. 318-334, julho.

SCHAFF, A. (1995) A sociedade informática. São Paulo: Brasiliense.

SPRANGER, E. (1948) Formas de vida. Psicologia y ética de la personalidad. Buenos Aires: Revista de Ocidente Argentino.

. (1960) El educador nato. Buenos Aires: Editorial Kapelusz S.A.

WILD, RH. \& Winniford, M. ( 1993 ) Remote collaboration among students using eletronic mail. Computers and Education. v.21, n. 3, p. $193-203$

\footnotetext{
(8) É bom esclarecer que em função de nosso objtivos neste texto estamos desconsiderando outros motivos que levam docentes a estarem desempregados.
} 